\title{
Status of family planning integration to HIV care in Amhara regional state, Ethiopia
}

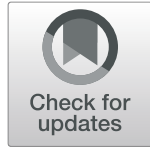

Zebideru Zewdie $^{1,2^{*}}$ D, Mezgebu Yitayal ${ }^{1}$, Yigzaw Kebede ${ }^{1}$ and Abebaw Gebeyehu ${ }^{3}$

\begin{abstract}
Background: Preventing unintended pregnancies among HIV positive women is one component of HIV prevention strategies. However, programs to prevent mother-to-child transmission (PMTCT) of HIV started in antenatal care. The objective of this study was to examine the status of family planning integration to HIV care from client and facility perspectives and identify factors associated with current family planning use.

Methods: A facility-based cross-sectional study was conducted from December 2017 to April 2018. Data were coded and double entered into EPI Info version 3.5.4 and exported to STATA version 14 for analysis. Bi-variable and multivariable logistic regression analyses were conducted to assess the association of variables with the current family planning use.

Results: A total of 518 HIV-positive women were included in the study. Among HIV-positive women, 35.3\% had an unmet need for family planning, and $21.4 \%$ responded that their pregnancies were unwanted. About two-thirds (68.1\%) of women were using a modern family planning method at the time of the study. Among women who were currently using family planning, $88.8 \%$ got the service from a family planning clinic in the same facility, and only $1.1 \%$ got the service from the HIV care unit. Women who were not knowledgeable on PMTCT (AOR 0.47, 95\% $\mathrm{Cl}=0.24-0.90$ ), divorced or separated women (AOR $0.19,95 \% \mathrm{Cl}=0.10-0.37$ ) and women in the age group of 2534 years (AOR $0.42,95 \% \mathrm{Cl}=0.20-0.88$ ) and $35-49$ years (AOR $0.41,95 \% \mathrm{Cl}=0.17-0.99$ ) were less likely to use modern family planning methods compared with those women who were knowledgeable, married and women in the age group of 15-24 years. Besides, women with higher income (AOR 2.12, 95\% Cl $=1.26-3.57$ ) were more likely to use modern family planning methods compared with women with lower incomes.
\end{abstract}

Conclusion: This study indicated that there is a high unmet need for family planning among HIV-positive women and low family planning services integration in the PMTCT/ART clinics. Efforts should be strengthened to tackle the factors which hinder the use of modern family planning and improve family planning service integration.

Keywords: Family planning integration, HIV positive women, Family planning use

\section{Background}

Women of childbearing age account for more than half of the world's Human Immunodeficiency Virus (HIV) cases and unintended pregnancy is high among HIV positive women [1]. Globally, nearly 1700 infants

\footnotetext{
* Correspondence: zebideru2002@gmail.com

${ }^{1}$ Institute of Public Health, College of Medicine and Health Sciences, University of Gondar, Gondar, Ethiopia

${ }^{2}$ Ethiopian Federal Ministry of Health, P.O. Box: 1234, Addis Ababa, Ethiopia

Full list of author information is available at the end of the article
}

become infected with HIV every day and $90 \%$ of these new infections are acquired through mother-to-child transmission (MTCT). The uses of family planning methods were among the strategies to prevent HIV positive birth [1]. This indicates that strengthening family planning services to HIV positive women gives an added value to prevent MTCT.

Globally, 222 million women either want to delay or avoid their pregnancy but they are not using modern contraceptive methods. This includes women who are 
HIV positive and those at risk of HIV [2-4]. Added to this, without appropriate prevention of mother to child transmission (PMTCT) interventions, about $50 \%$ of those infants born with HIV will die before their second birthdays [5-7]. Global commitments to eliminate new pediatric HIV infections recognized that preventing unintended pregnancies in HIV positive women is an essential HIV prevention strategy [8]. Therefore, preventing unintended pregnancies among women living with or at-risk of contracting HIV is a key component of the global HIV prevention strategy [8]. Family planning can also help achieve HIV prevention goals and improve maternal and child health outcomes [2].

Integrating family planning and HIV services is important to get information and services for both family planning and HIV care. Ensuring access to family planning options in PMTCT services saves time, increases uptake, improves the productivity of nurses, and decreases patient waiting times [9]. Additionally, this strategy promotes a one-stop shopping service that is user-friendly that improves the health outcomes of mothers and children [10]. There are different modalities of service integrations in different settings $[11,12]$. These include the provision of family planning within HIV testing, care, or treatment sites within PMTCT services, or within peer-outreach and community-based and home-based programs.

Ethiopia is among the 21 global priority countries with the highest number of pregnant women living with HIV who need PMTCT services [13]. These 21 countries accounted for $90 \%$ of the total number of pregnant women living with HIV that need services to prevent MTCT of HIV. In Ethiopia, there were 29,630 HIV positive mothers needing PMTCT services in 2017 and 8653 were from the Amhara region [14]. The adult HIV prevalence was also estimated to be $1.2 \%$ in 2014 [ 15 , 16]. The report also showed that the number of pregnancies among HIV positive mothers of the Amhara Region in 2014/2015 was 61.2\% [17].

According to the 2013/2014 report of the Ethiopian HIV Prevention and Control Office (HAPCO), 18.8\% of pregnant women on ART reported that their pregnancy was unintended [18]. The Federal Ministry of Health of Ethiopia has started integrating family planning with ART unit and HIV testing and counseling (HTC), and PMTCT within maternal, newborn and child health services since 2015. However, the programs to prevent MTCT of HIV continue to be executed as a narrow set of interventions that initiates in antenatal care. Besides, limited studies are observed on family planning integration in Ethiopia as well as the Amhara region. Therefore, this study aimed to examine the status of family planning integration to HIV care from client and facility perspectives and identify factors associated with current family planning use.

\section{Methods}

\section{Study design and area}

A cross-sectional study design was employed to assess the status of family planning integration to HIV care from client and facility perspectives in three referral hospitals (Gondar Referral Hospital, Dessie Referral Hospital, and Debre Birhan Referral Hospital) and three health centers (Gondar Town Health Center, Dessie Health Center and Debre Birhan Health Center) in Amhara region from December 2017 to April 2018. Amhara region is located in the northwestern part of Ethiopia.

\section{Study population and sampling}

All HIV-positive women who gave birth during the last 6 weeks to 24 months and who were on PMTCT follow up during the study period were included in the study. Also, facility audits in all selected health facilities were done to assess the availability of family planning services. However, all HIV-positive women who were seriously sick (women who were unable to communicate due to illness), who gave birth within the last 6 weeks, and who were pregnant were excluded from the study.

The sample size was determined using a single population proportion formula and calculated using EPI-info version 7.2.1.0 software. The sample was determined based on prevalence of unmet need for family planning which is $18.8 \%$ among women living with HIV [18] which is a proxy indicator to see family planning and HIV integration status, $5 \%$ margin of error, $95 \%$ confidence interval and design effect of 2 , and $10 \%$ nonresponse rate. Hence, the final sample size of the study was 517 HIV-positive women.

A multi-stage sampling technique with simple random sampling at each stage was employed. At the first stage, three referral hospitals and three health centers were selected by using a simple random sampling technique. In the second stage, HIV positive women who fulfilled the inclusion criteria were selected using a systematic random sampling technique from the PMTCT unit. The PMTCT registers were the sampling units and HIVpositive women on PMTCT follow up were the study participants. The number of study participants from each selected health facility was determined using proportional to population size calculation.

\section{Data collection procedures}

A structured questionnaire was used to collect the data. The structured questionnaire was prepared in English and translated to Amharic and then back to English to keep its consistency. The questionnaire was developed by reviewing journal articles, WHO and $\mathrm{MOH}$ PMTCT guidelines, and mother-baby pair cohort registers [1921] (Supplementary file 1). It consisted of the dependent variables: family planning integration status and current 
use of family planning; and independent variables such as personal factors (socio-demographic factor, maternal education, monthly income), reproductive and related factors (number of pregnancy, and number of ANC visits); knowledge about HIV testing and counseling, MTCT, and PMTCT; institutional factors (privacy of ART room, method mix for family planning); social factors (stigma and discrimination, partner disclosure); and desire to have children, unintended pregnancies, partner desire to have children, previous use of a contraceptive method and unmet need of family planning.

Twelve data collectors and four supervisors were recruited to administer the questionnaire using exit interviews. Exit interviews were conducted with a pre-tested structured questionnaire after taking informed consent from the study participants.

\section{Data processing and analysis}

Statistical analysis was undertaken using STATA version 14. Frequencies, proportions, and means were used to describe the data. A bivariate logistic regression analysis was carried out to see the association of socio-demographic factors, maternal and reproductive factors, and knowledge of MTCT of HIV on the current use of family planning. Variables associated with the outcome variable during bivariate logistic regression at $p$-value $\leq 0.2$ were included in the multiple logistic regression models, using backward fitting. Variables persisted to be associated with the outcome variable at $P \leq 0.05$ were considered to be significantly associated with the outcome variable.

The reliability of the tools was measured using Cronbach's alpha value and scales with a value above 0.7 were believed as reliable. Overall model fitness was measured using the log-likelihood ratio test. Based on the statistical significance of the probability of model chi-square less than 0.05 was supported the model to be a good fit. Hosmer and Lemeshow test goodness of fit were also used as a statistical value of more than 0.05 to characterize a logistic regression model as a better fit. A Wald test was used to test the statistical significance of the relationship between current family planning use and individual independent variables in the model.

Family planning integration was defined as the provision of family planning services (short and longacting family planning methods in addition to condom) within HIV testing, care, or treatment sites, and within the PMTCT unit. Unmet need for family planning was also defined as the proportion of women with no desire to become pregnant immediately before the most recent pregnancy but who are not using any method currently.

\section{Ethical considerations}

The University of Gondar Ethics Review Board approved the research proposal. A support letter was secured from the Amhara National Regional Health Bureau. Written informed consent was obtained from all research participants after the explanation of study objectives. The aims, benefits and the time it takes to complete the questionnaire were explained to the participants. Besides confidentiality, anonymity and their right to refuse from participation in the study were explained to them.

\section{Results \\ Socio-demographic characteristics of the study participants}

Five hundred eighteen HIV positive women participated in the study with a response rate of $100 \%$. The estimated sample size was 517 but one additional participant was included in the study due to her presence during the study period. Among the 518 HIV positive women interviewed, $389(75.1 \%)$ were orthodox Christians, 410 (79.2\%) were married, $113(21.8 \%)$ unable to read and write and 253(48.8\%) were housewives. The majority (66.4\%) of the respondents were in the age group of 25 34 years. The median age was 30 years (IQR: 27-33 years), and the median family monthly income was 1500 Birr. Three hundred eleven (60\%) HIV-positive women had one to two pregnancies at the time of study and $71.2 \%$ of the respondents' youngest child age was 3-12 months (Table 1).

\section{Fertility desires and family planning history}

About $85.9 \%$ of HIV-positive women gave birth after knowing their HIV status and 70.8\% HIV-positive women had used the family planning method before their last pregnancy. Overall, $33.2 \%$ of the respondents who already had children had the desire to have more children. Among HIV-positive women, 49.4\% intended to have another child after 2 years. For nearly two-thirds (59.9\%) of the study participants, the reason to have more children was to replace themselves. Among HIVpositive women, $35.3 \%$ had an unmet need for family planning, $21.4 \%$ ever had an unwanted pregnancy and $12.9 \%$ ever had induced abortion (Table 2).

\section{Family planning integration to HIV care and current use of family planning methods}

From 518 HIV-positive women, the majority (96.5\%) discussed family planning with their health care provider in the current visit and $68.1 \%$ were currently using a modern family planning method. The most frequent methods of contraception among family planning users were implant (35.9), followed by injectable (32.6\%), IUCD (14.2\%), condom (8.2\%) and $8.0 \%$ used Pills. Dual method use (condom and other methods such as pills, injectable, and IUCD) was reported by only $2.8 \%$. Among women who currently used family planning, 41.1\% preferred to get the service at ART/PMTCT clinic 
Table 1 Socio-demographic characteristics of study participants in Amhara Regional State, Ethiopia, 2018

\begin{tabular}{|c|c|c|}
\hline Variables & Frequency $(\boldsymbol{n}=518)$ & Percentage (\%) \\
\hline \multicolumn{3}{|l|}{ Age (Years) } \\
\hline $18-24$ & 57 & 11.0 \\
\hline $25-34$ & 344 & 66.4 \\
\hline $35-49$ & 117 & 22.6 \\
\hline \multicolumn{3}{|l|}{ Religion } \\
\hline Orthodox & 389 & 75.1 \\
\hline Muslim & 110 & 21.2 \\
\hline Protestant & 19 & 3.7 \\
\hline \multicolumn{3}{|l|}{ Marital Status } \\
\hline Single & 30 & 5.8 \\
\hline Married & 410 & 79.2 \\
\hline Divorced/Separated & 68 & 13.1 \\
\hline Widowed & 10 & 1.9 \\
\hline \multicolumn{3}{|l|}{ Education } \\
\hline Unable to read and write & 113 & 21.8 \\
\hline Able to read and write & 72 & 13.9 \\
\hline Primary education & 129 & 24.9 \\
\hline Secondary education & 111 & 21.4 \\
\hline Diploma & 66 & 12.8 \\
\hline Degree & 27 & 5.2 \\
\hline \multicolumn{3}{|l|}{ Occupation } \\
\hline Housewife & 253 & 48.8 \\
\hline Merchant & 96 & 18.5 \\
\hline Government employee & 86 & 16.6 \\
\hline Day laborer & 67 & 12.9 \\
\hline Commercial Sex Worker & 9 & 1.8 \\
\hline Farmer & 7 & 1.4 \\
\hline \multicolumn{3}{|l|}{ Ethnicity } \\
\hline Amhara & 463 & 89.4 \\
\hline Tigre & 28 & 5.4 \\
\hline Oromo & 27 & 5.2 \\
\hline \multicolumn{3}{|c|}{ Monthly family income (*Ethiopian Birr) } \\
\hline 0-1500 Birr & 269 & 51.9 \\
\hline 1501-3000 Birr & 154 & 29.7 \\
\hline > 3000 Birr & 95 & 18.4 \\
\hline \multicolumn{3}{|l|}{ Number of pregnancies } \\
\hline $1-2$ times & 311 & 60.0 \\
\hline 3-4 times & 175 & 33.8 \\
\hline$>5$ times & 32 & 6.2 \\
\hline \multicolumn{3}{|c|}{ Age of youngest child (months) } \\
\hline 2 months & 51 & 9.8 \\
\hline 3-12 months & 369 & 71.2 \\
\hline 13-24 months & 98 & 19.0 \\
\hline
\end{tabular}

$\square$ 27.21Ethiopian Birr $=1$ USD and $52.1 \%$ preferred to get the service in the family planning unit. However, among women who currently used family planning, the majority (88.8\%) got the service from the family planning clinic in the same facility and only $1.1 \%$ got the service from PMTCT/ART unit (Table 3).

\section{Family planning service audit}

In all selected health facilities there were separate service delivery points for family planning, PMTCT, and ART units. Two of the six health facilities had a poster in PMTCT and ART unit advertising family planning services. There was a limited choice of family planning methods available in those ART/PMTCT clinics providing family planning services. The health care workers of two ART clinics were trained on family planning. Among the six facilities, only two health facilities were providing family planning services other than male condoms at the HIV clinic (PMTCT/ART). Only oral contraceptives and condoms were available in those ART/ PMTCT clinics providing family planning services.

\section{Factors associated with current use of modern family planning methods}

The current use of modern family planning was significantly associated with maternal age, marital status, family income, and knowledge of MTCT. Women in the age group of $25-34$ years were $42 \%$ (AOR $0.42,95 \% \mathrm{CI}=$ $0.20-0.88$ ) and women in the group of $35-49$ years were $41 \%$ (AOR $0.41,95 \% \mathrm{CI}=0.17-0.99$ ) less likely to use modern family planning methods compared with women in the age group of 15-24 years. Divorced or separated women were $19 \%$ (AOR $0.19,95 \%$ CI $0.10-0.37$ ) less likely to use modern family planning methods compared with married women. Women with higher income were 2.12 (AOR 2.12, 95\% CI $=1.26-3.57$ ) times more likely to use modern family planning methods compared with women with lower income, and women who were not knowledgeable on PMTCT were 47\% (AOR 0.47, 95\% $\mathrm{CI}=0.24-0.90)$ less likely to use modern family planning methods than those who were knowledgeable (Table 4).

\section{Discussion}

In this study, $96.5 \%$ had discussed family planning with their health care provider in the current visit and $68.1 \%$ were currently using a modern family planning method. The finding was higher than the findings of Ghana (42.6\%) [22], Tanzania (54\%) [23], Malawi (51.2\%) [24], and Horro Guduru Wollega zone, Ethiopia (46.6\%) [25]. However, the current contraceptive use among respondents in this study is similar to studies among HIVpositive women in Cambodia (68.5\%), Zambia (69\%), Uganda (58\%), and Dire Dawa, Ethiopia (69\%) [26-29].

In this study, the most frequent method of contraception among HIV-positive women was Implant (35.9\%), 
Table 2 Fertility desires and unplanned pregnancies among HIV-positive women in Amhara Regional State, Ethiopia, 2018

\begin{tabular}{|c|c|c|}
\hline Variables & Frequency $(\boldsymbol{n}=518)$ & Percentage (\%) \\
\hline \multicolumn{3}{|l|}{ Gave birth after knowing HIV status } \\
\hline Yes & 445 & 85.9 \\
\hline No & 73 & 14.1 \\
\hline \multicolumn{3}{|l|}{ Use of family planning before your last pregnancy } \\
\hline Yes & 367 & 70.8 \\
\hline No & 151 & 29.2 \\
\hline \multicolumn{3}{|l|}{ Plan to be pregnant again } \\
\hline Yes & 172 & 33.2 \\
\hline No & 309 & 59.7 \\
\hline Do not know & 37 & 7.1 \\
\hline \multicolumn{3}{|l|}{ Reason to give birth $(n=172)$} \\
\hline To replace myself & 103 & 59.9 \\
\hline My partner wants & 51 & 29.7 \\
\hline To hide from people and avoid stigma and discrimination & 3 & 1.7 \\
\hline To hide my HIV status from my partner & 2 & 1.2 \\
\hline Do not know & 4 & 2.3 \\
\hline Others & 9 & 5.2 \\
\hline \multicolumn{3}{|l|}{ Preference to have children $(n=172)$} \\
\hline Within two year & 19 & 11.1 \\
\hline After two year & 85 & 49.4 \\
\hline When I feel healthy & 22 & 12.8 \\
\hline When my CD4 is high & 22 & 12.8 \\
\hline Do not know & 24 & 13.9 \\
\hline \multicolumn{3}{|l|}{ Number of children do you intend to have in the future $(n=172)$} \\
\hline One & 56 & 32.6 \\
\hline Two & 52 & 30.2 \\
\hline Three & 40 & 23.3 \\
\hline Don't know & 24 & 13.9 \\
\hline \multicolumn{3}{|l|}{ Ever had unwanted pregnancy } \\
\hline Yes & 111 & 21.4 \\
\hline No & 407 & 78.6 \\
\hline \multicolumn{3}{|l|}{ Ever had Induced abortion } \\
\hline Yes & 67 & 12.9 \\
\hline No & 451 & 87.1 \\
\hline \multicolumn{3}{|l|}{ Not have a plan to be pregnant again $(n=309)$} \\
\hline Not using FP currently (Unmet Need of FP) & 109 & 35.3 \\
\hline Using FP currently & 200 & 64.7 \\
\hline
\end{tabular}

followed by injectable (32.6\%). However, only $8.2 \%$ of the study participants were using condom. Even though the use of condoms is essential among HIV-positive women, the study revealed that the use of condoms and dual method use among respondents is low compared with similar studies in which show $79.6 \%$ male condom use in Ghana [22], and $42.9 \%$ in Dire Dawa, Ethiopia
[27]. This may be explained by the current study uses only women as study population and women might not directly control condom use. This will be a great concern for the risk of HIV transmission.

This study reveals that a high proportion of women use implant among family planning users which is higher compared with the findings of other studies 
Table 3 Family planning integration and current family planning use among HIV positive women in Amhara Regional State, Ethiopia, 2018

\begin{tabular}{|c|c|c|}
\hline Variables & Frequency $(\boldsymbol{n}=518)$ & Percentage (\%) \\
\hline \multicolumn{3}{|c|}{ Discussed about family planning with the health care provider in the current visit? } \\
\hline Yes & 500 & 96.5 \\
\hline No & 18 & 3.5 \\
\hline \multicolumn{3}{|l|}{ Using family planning method currently } \\
\hline Yes & 353 & 68.1 \\
\hline No & 165 & 31.9 \\
\hline \multicolumn{3}{|l|}{ Methods of Contraception used $(n=353)$} \\
\hline Implant & 127 & 35.9 \\
\hline Injectable & 115 & 32.6 \\
\hline IUCD & 50 & 14.2 \\
\hline Male condom & 29 & 8.2 \\
\hline Pills & 28 & 8.0 \\
\hline Others & 4 & 1.1 \\
\hline \multicolumn{3}{|l|}{ Dual method (condom and other method) $(n=353)$} \\
\hline Yes & 10 & 2.8 \\
\hline No & 343 & 97.2 \\
\hline \multicolumn{3}{|l|}{ Reason for choosing this contraceptive. $(n=353)$} \\
\hline Because it suits to my health & 239 & 67.7 \\
\hline Health professionals Preference & 62 & 17.6 \\
\hline From my friends experience & 50 & 14.1 \\
\hline Others & 2 & 0.6 \\
\hline \multicolumn{3}{|l|}{ Reason for using family planning method $(n=353)$} \\
\hline To space birth & 190 & 53.8 \\
\hline To stop birth & 107 & 30.3 \\
\hline To limit the number of child & 56 & 15.9 \\
\hline \multicolumn{3}{|l|}{ Place of getting family planning service $(n=353)$} \\
\hline From Family planning clinic in the same facility & 326 & 92.4 \\
\hline Family planning clinic in another service & 23 & 6.5 \\
\hline From PMTCT/ART unit & 4 & 1.1 \\
\hline \multicolumn{3}{|c|}{ Place of preference to get family planning service $(n=353)$} \\
\hline In family planning unit & 191 & 54.1 \\
\hline At ART/PMTCT clinic & 145 & 41.1 \\
\hline Private clinic & 17 & 4.8 \\
\hline \multicolumn{3}{|l|}{ Reason for not using family planning method $(n=165)$} \\
\hline I have no partner & 78 & 47.3 \\
\hline I am using condom & 30 & 18.2 \\
\hline I want to give birth & 25 & 15.2 \\
\hline Fear of side effects & 16 & 9.7 \\
\hline My partner doesn't agree & 10 & 6.1 \\
\hline Others & 6 & 3.6 \\
\hline
\end{tabular}


Table 4 Crude and multivariate logistic regression models for factors associated with current family planning use ( $n=518), 2018$

\begin{tabular}{|c|c|c|c|c|c|}
\hline \multirow{2}{*}{$\begin{array}{l}\text { Explanatory } \\
\text { Variable }\end{array}$} & \multicolumn{2}{|c|}{ Current use of modern FP } & \multirow{2}{*}{$\begin{array}{l}\text { Crude OR (95\% } \\
\text { Cl) }\end{array}$} & \multirow{2}{*}{$\begin{array}{l}\text { Adjusted OR } \\
(95 \% \mathrm{Cl})\end{array}$} & \multirow{2}{*}{$\begin{array}{l}\text { P- } \\
\text { value }\end{array}$} \\
\hline & Yes & No & & & \\
\hline \multicolumn{6}{|l|}{ Age } \\
\hline $15-24$ & 42 & 15 & 1 & 1 & \\
\hline $25-34$ & 232 & 112 & $0.73(0.39,1.39)$ & $0.42(0.20,0.88)$ & 0.022 \\
\hline $35-49$ & 79 & 38 & $0.74(0.36,1.50)$ & $0.41(0.17,0.99)$ & 0.048 \\
\hline \multicolumn{6}{|l|}{ Religion } \\
\hline Orthodox & 267 & 122 & 1 & 1 & \\
\hline Protestant & 10 & 9 & $0.50(0.20,1.28)$ & $0.37(0.12,1.07)$ & 0.069 \\
\hline Muslim & 76 & 34 & $1.02(0.64,1.61)$ & $1.12(0.66,1.90)$ & 0.651 \\
\hline \multicolumn{6}{|l|}{ Marital Status } \\
\hline Married & 302 & 108 & 1 & 1 & \\
\hline Single & 22 & 8 & $0.98(0.42,2.27)$ & $1.39(0.53,3.62)$ & 0.494 \\
\hline Widowed & 5 & 5 & $0.35(0.10,1.25)$ & $0.52(0.11,2.34)$ & 0.401 \\
\hline Divorced/Separated & 24 & 44 & $0.19(0.11,0.33)$ & $0.19(0.10,0.37)$ & 0.000 \\
\hline \multicolumn{6}{|l|}{ Education level } \\
\hline Unable to read \& write & 75 & 38 & 1 & 1 & \\
\hline Able to read \& write & 135 & 66 & $1.03(0.63,1.68)$ & $0.88(0.50,1.55)$ & 0.677 \\
\hline Secondary and above & 143 & 61 & $1.18(0.72,1.94)$ & $0.50(0.26,0.95)$ & 0.037 \\
\hline \multicolumn{6}{|l|}{ Occupation } \\
\hline Government employee & 69 & 17 & 1 & 1 & \\
\hline Merchant & 55 & 41 & $0.33(0.16,0.64)$ & $0.26(0.12,0.59)$ & 0.001 \\
\hline Housewife & 186 & 74 & $0.61(0.34,1.12)$ & $0.44(0.20,0.93)$ & 0.032 \\
\hline Day laborer & 43 & 33 & $0.32(0.15,0.64)$ & $0.37(0.15,0.91)$ & 0.031 \\
\hline \multicolumn{6}{|l|}{ Ethnicity } \\
\hline Amhara & 318 & 145 & 1 & 1 & \\
\hline Oromo & 19 & 8 & $1.08(0.46,2.53)$ & $1.42(0.53,3.83)$ & 0.482 \\
\hline Tigrie & 16 & 12 & $0.60(0.28,1.31)$ & $0.92(0.37,2.42)$ & 0.881 \\
\hline \multicolumn{6}{|c|}{ Monthly family income (Ethiopian Birr*) } \\
\hline$\leq 1500$ Birr & 164 & 105 & 1 & 1 & \\
\hline 1501-3000 Birr & 118 & 36 & $2.09(1.34,3.27)$ & $2.12(1.26,3.57)$ & 0.005 \\
\hline$>3000$ Birr & 71 & 24 & $1.89(1.12,3.19$ & $1.80(0.96,3.36)$ & 0.064 \\
\hline \multicolumn{6}{|l|}{ No of Pregnancies? (Gravida) } \\
\hline $1-2$ times & 207 & 104 & 1 & 1 & \\
\hline 3-4 times & 128 & 47 & $1.36(0.90,2.05)$ & $1.48(0.92,2.39)$ & 0.100 \\
\hline$>5$ times & 18 & 14 & $0.64(0.30,1.34)$ & $0.58(0.24,1.40)$ & 0.232 \\
\hline \multicolumn{6}{|l|}{ Knowledge about PMTCT } \\
\hline Knowledgeable & 324 & 142 & 1 & 1 & \\
\hline Not Knowledgeable & 29 & 23 & $0.55(0.30,0.98)$ & $0.47(0.24,0.90)$ & 0.024 \\
\hline \multicolumn{6}{|l|}{ Place of birth youngest child } \\
\hline In this hospital & 305 & 142 & 1 & 1 & \\
\hline In another hospital & 45 & 18 & $1.16(0.65,2.08)$ & $1.39(0.72,2.67)$ & 0.313 \\
\hline Deliver at home & 3 & 5 & $0.27(0.06,1.18)$ & $0.24(0.04,1.24)$ & 0.089 \\
\hline \multicolumn{6}{|l|}{ Disclosure status } \\
\hline Yes & 313 & 132 & 1 & 1 & \\
\hline
\end{tabular}


Table 4 Crude and multivariate logistic regression models for factors associated with current family planning use ( $n=518), 2018$ (Continued)

\begin{tabular}{|c|c|c|c|c|c|}
\hline \multirow{2}{*}{$\begin{array}{l}\text { Explanatory } \\
\text { Variable }\end{array}$} & \multicolumn{2}{|c|}{ Current use of modern FP } & \multirow{2}{*}{$\begin{array}{l}\text { Crude OR (95\% } \\
\text { Cl) }\end{array}$} & \multirow{2}{*}{$\begin{array}{l}\text { Adjusted OR } \\
(95 \% \mathrm{Cl})\end{array}$} & \multirow{2}{*}{$\begin{array}{l}P \text { - } \\
\text { value }\end{array}$} \\
\hline & Yes & No & & & \\
\hline No & 40 & 33 & $0.51(0.30,0.84)$ & $0.81(0.43,1.51)$ & 0.516 \\
\hline
\end{tabular}

conducted in Ghana (7.1\%), Tanzania (13.3\%), and Zambia (8\%) [22-23,28]. This may be explained by the availability of service at a lower health facility level (the service is provided by a health extension worker at a health post level in Ethiopia).

The study reveals that, despite being HIV-positive, $33.2 \%$ of the respondents who already had children had the desire to have more children which is much higher than the finding of a study in Cambodia (7.3\%) [26]. The finding is consistent with the study conducted in Dire Dawa, Ethiopia where 32\% of respondents had the desire to have more children [27]. The study also reveals that $60 \%$ of HIV-positive women had one to two pregnancies at the time of study and $85.9 \%$ gave birth after knowing their HIV status in this study. Low risk of MTCT after ARV may favor this outcome among HIV-positive women.

The integration of family planning and HIV services greatly helps in supporting the implementation of prong two at all levels of program and health service management. Addressing women's reproductive health needs holistically strengthens the impact of both family planning and HIV services [10]. The integration of family planning services to HIV services can increase access and uptake [2, 9]. Family planning integration has increased the use of family planning by $12.9 \%$ in Kenya [30]. But, in this study, only $1.1 \%$ got the service from PMTCT/ART unit. The facility audit also showed that among the six facilities, only two health facilities were provided with family planning services other than male condoms at the HIV clinic (ART/PMTCT unit). There was a limited choice of family planning methods available in those ART/PMTCT clinics providing family planning services. Health workers who were working in only two ART clinics had been trained in family planning. This shows the integration of services was poor. This finding is in line with the findings of a study conducted in five countries of Africa (Ethiopia, Kenya, Rwanda, South Africa, and Uganda) [31] on integration of family planning to HIV care, which shows that most ART clinics had only one or two providers on duty and many of these providers indicated that they did not have family planning training. This study also has a similar finding with a study conducted in Uganda which showed that ART clinic did not have contraceptives onsite [32]. Similar studies conducted in Ethiopia and South Africa showed the presence of weak integration of family planning services to chronic HIV care [27, 33]. A study conducted in Kenya showed that $73 \%$ of women and $71 \%$ of men thought that they or their partner would be more likely to use family planning if the services were offered at the HIV clinic [34]. Besides, a study in Zambia revealed that most respondents said they would access family planning services had it been available within the ART clinic [28].

This study indicates that a high proportion of women with no desire to be pregnant were not using any modern method of contraception and there was no method mix at ART/PMTCT unit in those facilities that integrate the service. This might have been a factor for low uptake of modern family planning and hence strengthening the integration of family planning services in the Adult HIV clinic and PMTCT clinic is important.

The unmet need for family planning among HIVpositive women in this study is higher compared to the unmet need among the general population in Amhara Region, Ethiopia (17\%) [35]. This is also supported by a study conducted in Dire Dawa, Ethiopia which shows a high unmet need for family planning (36\%) among women living with HIV [27]. The finding is comparatively higher than the findings reported from Kenya (20\%) [31], Ghana 27.8\% [22], Western Ethiopia (15.4\%) [36], and Hawassa city Ethiopia (19.1) [37]. This study also indicates that $21.4 \%$ of participants ever had an unwanted pregnancy and $12.9 \%$ ever had induced abortion.

In this study maternal age, marital status, family income, and knowledge about MTCT were strongly associated with the current use of contraception. Women in the age group of 25-34 years and women in the group of 35-49 years were less likely to use modern family planning methods compared with women in the age group of 15-24 years. This is consistent with the findings of studies conducted in Malawi [38], and Ethiopia [39]. Divorced or separated women were less likely to use modern family planning methods compared with married women. This is in line with studies done in Kenya [40], Nigeria [41], and Ethiopia [39]. This study reveals that women with higher income were more likely to use modern family planning methods compared with women with lower income and women who were not knowledgeable on MTCT were less likely to use modern family planning methods than those who were knowledgeable. Similar findings were found from studies conducted in Nigeria [41], and Ethiopia [39]. This might 
be due to the effect of women's financial capacity and knowledge about MTCT which may enable women decision making autonomy on the couple's family planning use. This highlights the need to devise incomegenerating strategies and increase the knowledge of women about MTCT of HIV.

Limitations of this study, due to the cross-sectional nature of the data, cause and effect relationship between the dependent and independent factors could be weak; and social desirability bias may not be avoidable even though data collectors were trained. Besides, current contraceptive use was based on self-report by the women who might have reported what was perceived as socially acceptable or correct, which would have overestimated the estimates obtained in this study. Despite these limitations, the data being gathered have a better description of family planning among HIV positive women.

\section{Conclusion}

The study shows that there is a high unmet need for family planning among HIV-positive women and low integration of family planning services in PMTCT/ART clinics. Knowledge about MTCT of HIV, family income, marital status, and maternal age are predictors of current contraceptive use. Reducing the unmet need for modern family planning methods by improving the provision of family planning services to HIV-positive women through the integration of family planning to HIV care and increasing awareness of HIV positive women about PMTCT is recommended for prevention of mother to child transmission of HIV.

\section{Supplementary information}

Supplementary information accompanies this paper at https://doi.org/10. 1186/s12884-020-2838-x.

Additional file 1: English Version Questionnaires

\section{Abbreviations}

AOR: Adjusted odds ratio; ART: Antiretroviral therapy; Cl: Confidence interval; FP: Family planning: HCT: HIV counseling and testing; HIV: Human immunodeficiency virus; MTCT: Mother-to-child transmission; OR: Odds ratio; PMTCT: Prevention of mother-to-child transmission

\section{Acknowledgments}

The authors would like to thank Mr. Awraris Hailu, for his critical review of draft versions of this manuscript. We would also like to acknowledge data collectors and study participants.

\section{Authors' contribution}

Z.Z., Y.M., K.Y. and G.A. designed the research study. Z.Z., Y.M., K.Y. and G.A. performed the research. Z.Z. analyzed the data. Z.Z. wrote the draft paper. Z.Z., Y.M., K.Y. and G.A. critically review the paper. All authors approved the final manuscript and agree to be accountable for all aspects of the work.

\section{Funding}

Not applicable.

\section{Availability of data and materials}

The datasets used during the current study are available from the corresponding author on reasonable request.

\section{Ethics approval and consent to participate}

The University of Gondar Ethics Review Board approved the research proposal. Support letter from the Amhara National Regional Health Bureau was secured. Written informed consent was obtained from all research participants after the explanation of study objectives. The aim, benefits and risks of participation in the study, the time she will take to complete the questionnaire, how confidentiality, anonymity and privacy were maintained and their right to refuse to participate in the study was explained to them.

\section{Consent for publication}

We have got informed written consent from participants for possible publication.

\section{Competing interests}

The authors report no conflicts of interest in this work.

\section{Author details}

${ }^{1}$ Institute of Public Health, College of Medicine and Health Sciences, University of Gondar, Gondar, Ethiopia. ${ }^{2}$ Ethiopian Federal Ministry of Health, P.O. Box: 1234, Addis Ababa, Ethiopia. ${ }^{3}$ Amhara National Regional State Health Bureau, Bahir Dar, Ethiopia.

Received: 18 December 2018 Accepted: 25 February 2020

Published online: 06 March 2020

\section{References}

1. Wilcher R, Petruney T, Reynolds HW, Cates W. From effectiveness to impact: contraception as an HIV prevention intervention. Sex Transm Infect. 2008; 84(Suppl II):54-60.

2. USAID. Family Planning and HIV Prevention Integration,Issue Brief. 2012.

3. Foreman M, Spieler J. Contraceptive evidence, Quesion and answers. Washington DC, USA, 2013.

4. FHI 360, USAID. Facts for Family Planning. 2012.

5. WHO. Strategic Vision 2010-2015: Preventing mother-to-child transmission of HIV to reach the UNGASS and millennium development goals. Geneva: WHO Press; 2011.

6. UNAIDS. Children and pregnant women living with HIV, The GAP Report 2014. Geneva: UNAIDS; 2014

7. Innes S, Lazarus E, Otwombe K, Liberty A, Germanus R, Van Rensburg AJ, et al. "Early severe HIV disease precedes early antiretroviral therapy in infants: are we too late?". J Int AIDS Soc. 2014:(8914):1-6.

8. UNAIDS. Report of the global AIDS epidemic 2013. Geneva: UNAIDS; 2013.

9. IPPF, UNFPA, WHO. SRH and HIV linkages compendium: indicators \& related assessment tools. London: IPPF, UNFPA, WHO; 2014.

10. $\mathrm{MOH}$. Implementation manual for integrated HIV/AIDS and family planning services. Addis Ababa: MoH; 2015.

11. FHI360. Integrating Family Planning into HIV Programs: Evidence-Based Practices. 2013.

12. WHO. Strategic Considerations for Strengthening the Linkages between Family Planning and HIV/AIDS Policies, Programs, and Services. Geneva: WHO; 2009.

13. UNAIDS. The gap report. 2014. Geneva: UNAIDS; 2014. Available from: unaids.org.

14. EPHI. HIV related estimates and projections for Ethiopia-2017. Addis Ababa: EPHI; 2017.

15. CSA, ICF. Ethiopia demographic and health survey 2011. Addis Ababa, Ethiopia and Calverton: Central Statistical Agency and ICF International; 2012.

16. EPHI. HIV related estimates and projections for Ethiopia. Addis Ababa: EPHI; 2014.

17. ARHB. Annual report. Bahir Dar: Amhara Health Bureau; 2015.

18. FHAPCO. Countries progress report on the HIV respons. Addis Ababa: FHAPCO; 2014

19. WHO. Guideline on When to Start Antiretroviral Therapy and on PreExposure Prophylaxis for HIV, 2015.

20. MoH. Mother baby pair cohort register. Addis Ababa: MoH; 2013. 
21. MoH. National guidline for the prevention of mother to child transmission of HIV. Addis Ababa: MoH; 2017.

22. Laryea D, Amoako Y, Spangenberg K, Frimpong E, Kyei-Ansong J. Contraceptive use and unmet need for family planning among HIV positive women on antiretroviral therapy in Kumasi Ghana. BMC Womens Health. 2014;14(126):1-8.

23. Damian J, Johnston M, George EM, Beatrice T, Msuya SE. Prevalence and factors influencing modern contraceptive use among HIV-positive women in Kilimanjaro region, northern Tanzania. Contracept Reprod Med. 2018;3(7):1-9.

24. Habte D, Namasasu J. Family planning use among women living with HIV: knowing HIV positive status helps - results from a national survey Malawi. Reprod Health 2015;12(41):1-11.

25. Tsegaye R. Family planning need of people living with HIV/AIDS in antiretroviral therapy clinics of Horro Guduru Wollega zone, Ethiopia. BMC Res Notes. 2017;10(581):1-6.

26. Nakaie N, Tuon S, Nozaki I, Yamaguchi F, Sasakia Y, Kakimoto K. Family planning practice and predictors of risk of inconsistent condom use among HIV-positive women on anti-retroviral therapy in Cambodia. BMC Public Health. 2014;14(170):1-9.

27. Kassa M, Abera G, Bekele D, Girma B, Adamou B. Assessment of Integration of Family Planning into HIV/AIDS Care and Treatment Services in Health Facilities in Dire Dawa City Administration. MEASURE Evaluation PRH; 2014.

28. Hancock NL, Chibwesha CJ, Bosomprah S, Newman J, Mbewe M, Sitali ES, et al. Contraceptive use among HIV-infected women and men receiving antiretroviral therapy in Lusaka, Zambia: a cross-sectional survey. BMC Public Health. 2016;16(392):1-8.

29. Wanyenze RK, Tumwesigye NM, Kindyomunda R, Beyeza-Kashesya J, Atuyambe L, Kansiime A, et al. Uptake of family planning methods and unplanned pregnancies among HIV-infected individuals: a cross-sectional survey among clients at HIV clinics in Uganda. J Int AIDS Soc. 2011;14(35):1-11.

30. Kosgei R, Lubano K, Shen C, Wools-Kaloustian K, Musick B, Siika A, et al. Impact of Integrated Family Planning and HIV Care Services on Contraceptive Use and Pregnancy Outcomes: A Retrospective Cohort Study. Acquir Immune Defic Syndr. 2011;58(5):e121-6.

31. FHI. Study of Family Planning and HIV Integrated Services in Five Countries. 2010.

32. Wanyenze R, Matovu J, Kamya M, Tumwesigye N, Nannyonga M, Wagner G. Fertility desires and unmet need for family planning among HIV infected individuals in two HIV clinics with differing models of family planning service delivery. BMC Womens Health. 2015;15(5):1-12.

33. Horwood C, Haskins L, Vermaak K, Phakathi S, Subbaye R, Doherty T. Prevention of mother to child transmission of HIV programme in KwaZuluNatal, South Africa: an evaluation of PMTCT implementation and integration into routine maternal, child and women's health services. Trop Med Int Health. 2010;15(9):992-9.

34. Newmann S, Grossman D, Blat C, Onono M, Steinfeld R, Bukusi E, et al. Does integrating family planning into HIV care and treatment impact intention to use contraception? Patient perspectives from HIV-infected individuals in Nyanza Province, Kenya. Int J Gynecol Obstet. 2013;123:e16-23.

35. CSA, ICF. Ethiopia demographic and health survey 2016. Addis Ababa, Ethiopia, and Rockville: Central Statistical Agency and ICF International; 2016.

36. Feyissa T, Melka A. Demand for modern family planning among married women living with HIV in Western Ethiopia. Plos one. 2014;9(11):e113008.

37. Feyssa M, Tsehay $Y$, Tadesse A. Unmet Need for Family Planning Among Women in HIV/AIDS Care at Antiretroviral Treatment Clinic in South Ethiopia: A Challenge to Prevention of Mother to Child Transmission. J AIDS Clin Res. 2015;6(469):1-6.

38. Krashin JW, Haddad LB, Tweya H, Chiwoko J, Ng'ambi W, Samala B, et al. Factors associated with desired fertility among HIV-positive women and men attending two urban clinics in Lilongwe, Malawi. Plos one. 2018;13(6):e0198798.

39. Mitiku K, Mulugeta S, Lemessa B. Modern Contraceptive Utilization and Associated Factors among HIV Positive Women on Antiretroviral Therapy in Mizan- Tepi Teaching and Referral Hospital, South-West Ethiopia. J Contracept Stud. 2017;2(2):10.

40. Njuguna E, llovi S, Muiruri P, Mutai K, Kinuthia J, Njoroge P. Factors influencing the utilization of family planning services among HIV infected women in a Kenyan health facility. Int J Reprod Contracept Obstet Gynecol. 2017;6(5):1746-52.

41. Ashimi AO, Amole TG, Abubakar MY, Ugwa EA. Fertility desire and utilization of family planning methods among HIV-positive women attending a tertiary hospital in a suburban setting in Northern Nigeria. Trop J Obstet Gynaecol. 2017;34:54-60

\section{Publisher's Note}

Springer Nature remains neutral with regard to jurisdictional claims in published maps and institutional affiliations.
Ready to submit your research? Choose BMC and benefit from:

- fast, convenient online submission

- thorough peer review by experienced researchers in your field

- rapid publication on acceptance

- support for research data, including large and complex data types

- gold Open Access which fosters wider collaboration and increased citations

- maximum visibility for your research: over $100 \mathrm{M}$ website views per year

At BMC, research is always in progress.

Learn more biomedcentral.com/submissions 